\title{
Mitigating SARS-CoV-2 Transmission in Hispanic and Latino Communities—Prince William Health District, Virginia, June 2020
}

\author{
Elizabeth Davlantes ${ }^{1} \cdot$ Ashley Tippins $^{1} \cdot$ Catherine Espinosa $^{1} \cdot$ Hannah Lofgren $^{1} \cdot$ Sarah Leonard $^{1} \cdot$ Monica Solis $^{2}$. \\ Andrea Young $^{2} \cdot$ Denise Sockwell $^{2} \cdot$ Alison Ansher $^{2}$
}

Received: 1 December 2020 / Revised: 11 January 2021 / Accepted: 12 January 2021 / Published online: 4 February 2021

(C) This is a U.S. government work and not under copyright protection in the U.S.; foreign copyright protection may apply 2021

\begin{abstract}
Objectives To identify factors contributing to disproportionate rates of COVID-19 among Hispanic or Latino persons in Prince William Health District, Virginia, and to identify measures to better engage Hispanic and Latino communities in COVID-19 mitigation. Methods Data collection proceeded via three methods in June 2020: a quantitative survey of Hispanic or Latino residents, key informant interviews with local leaders familiar with this population, and focus group discussions with Hispanic or Latino community members.

Results Those who worked outside the home, lived in larger households, or lived with someone who had tested positive were more likely to report testing positive for SARS-CoV-2 (unadjusted odds ratios of 2.5, 1.2, and 12.9, respectively). Difficulty implementing COVID-19 prevention practices (reported by $46 \%$ of survey respondents), immigration-related fears (repeatedly identified in qualitative data), and limited awareness of local COVID-19 resources (57\% of survey respondents spoke little or no English) were identified. Survey respondents also reported declines in their food security (25\%) and mental health (25\%).

Conclusions Specific attention to the needs of Hispanic or Latino communities could help reduce the burden of COVID-19. The investigation methods can also be used by other jurisdictions to evaluate the needs of and services provided to diverse underserved populations.
\end{abstract}

Keywords COVID-19 $\cdot$ Hispanic $\cdot$ Latino $\cdot$ Spanish

\section{Introduction}

The Prince William Health District (PWHD) is located in northern Virginia, and the area includes unincorporated Prince William County and the cities of Manassas and Manassas Park. Hispanic and Latino residents of PWHD have been disproportionately affected by coronavirus disease 2019 (COVID-19); these persons represent $25 \%$ of the area's population but $55 \%$ of all cases for which ethnicity data are available (as of November 23, 2020) [1,2].

While COVID-19 case counts by ethnicity are not currently compiled nationally, similar trends have been noted in almost every state [3, 4]. The Hispanic or Latino population is the largest ethnic minority group in the USA, accounting for $18 \%$ of the nation's population, more than 60 million people [5].

Elizabeth Davlantes

lyo2@cdc.gov

1 Centers for Disease Control and Prevention, Atlanta, GA, USA

2 Virginia Department of Health, Manassas, VA, USA
Nationwide, communities of color are at increased risk for COVID-19 due in part to long-standing systemic health and social inequities [6-8].

In June 2020, an investigation was undertaken to evaluate risk factors for disproportionate rates of COVID-19 among Hispanic or Latino persons in PWHD. While many studies have identified disparities in rates of COVID-19 disease among such persons nationwide, more actionable solutions may help better protect these populations [9-11]. Furthermore, the Hispanic or Latino population in the USA is not homogeneous, and COVID-19 mitigation strategies targeted to specific needs identified at the community level may be most effective [4].

This report describes a rapid, multi-pronged method of assessing the needs and limitations of PWHD's Hispanic or Latino residents during the COVID-19 pandemic.

\section{Methods}

The investigation took place over three weeks in June 2020 and consisted of a quantitative survey, key informant interviews, and focus group discussions. 
A quantitative survey was administered to Hispanic or Latino residents of three Zone Improvement Plan (ZIP) codes of PWHD which had been identified as COVID-19 hotspots. The survey was administered to people who had tested positive for SARS-CoV-2 (the virus causing COVID-19) via reverse transcription-polymerase chain reaction (RT-PCR), those who had tested negative, and those who had not been tested. Survey questions focused on COVID-19 prevention strategies, the pandemic's effect on daily life, and reported SARS-CoV-2 testing results of participants and their household members.

Information on SARS-CoV-2 testing status and ethnicity was derived from records from free mass testing events held by PWHD in May 2020. Home addresses of people identifying as Hispanic or Latino were randomly selected from among these records, proportionate to the Hispanic or Latino population in Manassas, Manassas Park, and unincorporated Prince William County. Surveys were administered to consenting adults who lived at these addresses; no attempts were made to specifically reach the individuals who had attended the testing events. Data from untested people were collected from a convenience sample of Hispanic or Latino residents approached at highly trafficked community sites, such as grocery stores.

Survey data were entered by trained interviewers into a REDCap v 9.5.25 database (Vanderbilt University, Nashville, TN) maintained by the PWHD. Data were cleaned and analyzed in SAS v 9.4 (SAS Institute, Cary, NC). Data were weighted on sex, age, and location (ZIP code and residence in a city or the county). Associations between risk factors and any reported positive SARS-CoV-2 diagnostic results were determined using appropriate statistical tests, such as Pearson's chi-square and tests of group difference. To further explore significant risk factors associated with a positive SARS-CoV-2 test, univariable and multivariable logistic regression models were used to estimate odds ratios (ORs) and 95\% confidence intervals, adjusting for age, sex, and location (significance level $p<0.05$ ).

In-depth key informant interviews were performed with a convenience sample of health sector leaders and Hispanic or Latino community advocates identified by the PWHD. Key informant participants included school social workers, staff at local hospitals and clinics, outreach personnel for Virginia's Medicaid program, and leaders of Hispanic or Latino community empowerment organizations. All interview participants worked extensively with local Hispanic or Latino communities, and many also identified as Hispanic or Latino themselves. Interviews assessed knowledge, attitudes, and practices regarding COVID-19 and barriers to accessing mitigation services among Hispanic or Latino communities.

Three focus group discussions were also held with Hispanic or Latino residents of the three ZIP codes to flesh out themes identified in the survey and key informant interviews. Focus group participants were purposefully selected by community leaders to represent the diversity of the population, including diversity in level of education, age, gender, employment status, immigration status, and English fluency. Two focus group discussions were conducted in Spanish, while the third was conducted in English at the request of that group's participants.

Interviews and discussions followed a standardized guide with open-ended questions and were audio recorded if all participants provided verbal consent. Written notes were also taken during all encounters. Recordings were transcribed in true verbatim style using Express Scribe Transcription Software Pro v 9.11 (NCH Software, Inc., Greenwood Village, CO). Transcriptions were coded and analyzed in Dedoose v 8.3.217 (Dedoose, Los Angeles, CA) using the grounded theory method and inductive approach to qualitative analysis. For key informant interviews that were not audio recorded, written interview notes were examined. Recurring ideas were identified, grouped into themes, and coded.

All participants provided verbal informed consent, and no personally identifying information was collected. This activity was reviewed by the Centers for Disease Control and Prevention (CDC) and was conducted consistent with applicable federal law and CDC policy. ${ }^{1}$

\section{Results}

"This pandemic has affected Hispanics in all senses, economically, socially, mental health... the impact this has had on Hispanics is strong." -focus group participant

Data for this investigation were collected from 177 surveys, 6 key informant interviews, and 3 focus group discussions (15 total focus group participants). Table 1 depicts the demographics of the survey sample; the effective sample size for the survey after weighting was 161 . Saturation was reached for key informant interviews and focus group discussions.

Findings from the survey respondents and themes from the key informant interviews and focus groups (collectively referred to as qualitative evaluation participants) are summarized by topic below. The term "investigation participants" precedes findings identified among all three data collection modalities. As many common themes were identified among

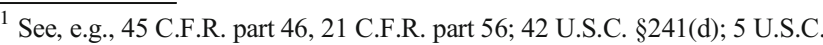
§552a; 44 U.S.C. $\$ 3501$ et seq.
} 
Table 1 Survey respondent characteristics $(n=161)$ - June 2020

\begin{tabular}{|c|c|c|}
\hline & $n$ & $\%$ \\
\hline Mean age (IQR) & $40.6(31-49)$ & \\
\hline \multicolumn{3}{|l|}{ Sex } \\
\hline Female & 77 & 47.5 \\
\hline Male & 82 & 51.0 \\
\hline \multicolumn{3}{|l|}{ Jurisdiction } \\
\hline Prince William County & 64 & 39.8 \\
\hline Manassas & 83 & 51.7 \\
\hline Manassas Park & 11 & 7.0 \\
\hline Mean household size (IQR) & $5.6(4-7)$ & \\
\hline \multicolumn{3}{|l|}{ English proficiency (respondent) } \\
\hline Very well or well & 32 & 20.1 \\
\hline Not well or not at all & 91 & 56.5 \\
\hline Missing & 37 & 23.0 \\
\hline \multicolumn{3}{|l|}{ Education } \\
\hline Less than high school & 98 & 60.9 \\
\hline High school or higher & 61 & 37.9 \\
\hline \multicolumn{3}{|l|}{ Country of origin } \\
\hline El Salvador & 57 & 35.2 \\
\hline Mexico & 38 & 23.3 \\
\hline Guatemala & 25 & 15.7 \\
\hline Honduras & 13 & 8.3 \\
\hline USA & 12 & 7.1 \\
\hline Other & 15 & 9.3 \\
\hline \multicolumn{3}{|l|}{ Employed (respondent) } \\
\hline Yes & 93 & 57.5 \\
\hline \multicolumn{3}{|l|}{ Occupation $(n=93)$} \\
\hline Construction/landscaping & 40 & 43.0 \\
\hline Restaurant & 15 & 16.1 \\
\hline Retail & 6 & 6.5 \\
\hline Cleaning & 9 & 9.2 \\
\hline Healthcare/childcare/professional & 7 & 7.5 \\
\hline Other & 16 & 17.2 \\
\hline \multicolumn{3}{|l|}{ Employed (household members) } \\
\hline Yes & 130 & 80.9 \\
\hline \multicolumn{3}{|l|}{ Occupation $(n=130)$} \\
\hline Construction/landscaping & 68 & 52.3 \\
\hline Restaurant & 29 & 22.2 \\
\hline Retail & 21 & 16.2 \\
\hline Cleaning & 10 & 7.7 \\
\hline Healthcare/childcare/professional & 24 & 18.5 \\
\hline Other & 24 & 18.5 \\
\hline
\end{tabular}

Survey weights applied; sample weighted on age, sex, and jurisdiction. Unweighted sample size $n=177$

Results may not sum to $100 \%$. Some questions allowed multiple responses, while others had a small amount of missing data

the three data collection modalities, their findings are presented together. In general, there was very little discordance between the results from these three modalities, highlighting the robustness of the findings.

\section{COVID-19 Knowledge and Prevention Practices}

\begin{abstract}
"I've gone crazy with cleaning, with disinfectant... when I get home from work something I do is disinfect the whole house, the door, the handles, everything gets disinfected, with bleach, I'm actually dusting with bleach. I said 'No, I'm not going to be afraid, we're going to continue to lead a normal life."'-focus group participant
\end{abstract}

Overall, investigation participants had a good understanding of COVID-19 prevention practices. Almost all survey respondents reported knowing the importance of wearing masks (86\%) and doing so in their daily lives (82\%). Most also reported being aware of the importance of (67\%) and practicing (61\%) hand hygiene. However, fewer survey respondents endorsed social distancing, with 59\% reporting awareness of and $53 \%$ practicing this intervention. Less than a fifth of survey respondents acknowledged wearing gloves (19\% aware of, $20 \%$ practicing), staying home as often as possible $(15 \%$, $15 \%)$, and covering coughs and sneezes $(5 \%, 1 \%)$ as prevention measures. Focus group participants emphasized the importance of frequently disinfecting household objects and reported spending many hours per week cleaning and procuring cleaning supplies.

However, $46 \%$ of survey respondents reported difficulty adhering to COVID-19 prevention practices. Most commonly reported difficulties were an inability to social distance at work $(27 \%)$ or at essential service providers such as grocery stores or laundromats (17\%). An additional constraint reported was procuring masks, gloves, disinfectants, and other cleaning supplies; qualitative evaluation participants described prolonged stockouts at local stores, price gouging, and poor-quality items for sale. Participants compensated for this by reusing items they knew should not be reused (disposable masks and gloves) and substituting with household materials (vinegar as disinfectant, pantyliners as mask filters).

\section{COVID-19 Information Sources}

"Information. Information is what is most helpful. The more informed we are, the more together we are as a community or as neighbors, this makes it stronger- or to say, this makes it a little more difficult for the virus to get through or spread."-focus group participant

In general, investigation participants could not identify a single, trustworthy source of information for COVID-19. Older survey respondents reported using Spanish-language 
television ( $59 \%$ of respondents aged 55 years or more), while younger respondents most commonly used social media and Internet search engines $(62 \%$ of respondents aged $18-$ 34 years). Hospitals and clinics were mentioned as secondary sources of COVID-19 information among all surveyed age groups (18\% of respondents). Focus group participants identified ministries of health from their countries of origin as additional sources. Other noted sources included trusted local leaders, such as clergy or prominent Hispanic or Latino business owners. Many qualitative evaluation participants reported feeling confused and overwhelmed by COVID-19 information they described as variable and conflicting. Focus group participants expressed interest in an opt-in text messaging service that would send periodic COVID-19 updates and tips to cell phones, suggesting that the same platform providing emergency alerts to the area could also offer this.

Among survey respondents, 57\% spoke little or no English and $61 \%$ did not finish high school. Qualitative evaluation participants reported that most COVID-19 information specific to PWHD was only in English, not geared towards the needs of Hispanic or Latino communities, and text-heavy with less emphasis on videos, images, and graphics. Investigation participants repeatedly requested a single, up-to-date source for trustworthy local COVID-19 information in Spanish. The absence of such information in Spanish was interpreted by some qualitative evaluation participants as the local government's disinterest in their well-being.

\section{Healthcare-Seeking Behavior and SARS-CoV-2 Testing}

"I think now... even though they realize what it is, I don't think they completely...[pauses] can... follow the recommendations because priorities are, again, feeding their family and paying their rent. How to survive is their priority." -key informant

A total of $82 \%$ of survey respondents reported they would seek medical care when concerned about COVID-19. However, qualitative evaluation participants in general felt that the time to go to the doctor was "when you can't breathe" (shortness of breath is considered an emergency COVID-19 warning sign by the CDC) [12]. Reported barriers to accessing healthcare included high healthcare costs or lack of health insurance, fear of being identified as undocumented, inability to visit during normal business hours due to work obligations, and difficulty communicating with English-speaking healthcare providers. Key informant interview participants emphasized that immigration-related fears cannot be overstated and that some Hispanic or Latino community members pay hundreds of dollars at private clinics because of fears they will be reported to authorities at clinics offering free services.
Focus group participants repeatedly reported difficulty in accessing SARS-CoV-2 testing. Participants reported that information on local testing site locations, hours, costs, and other requirements was not centralized and was available only in English. Participants noted that some sites required identification, deterring people who are undocumented, while other sites required a printed ticket, deterring people without access to computers and printers. Furthermore, participants reported that some sites would only test symptomatic individuals. Participants were frequently unaware of free testing sites and paid several hundred dollars for tests. Once tested, many participants reported never being notified of their results. Immigration-related fears were also commonly described; some qualitative evaluation participants expressed avoiding government testing sites out of concern that accepting assistance could impact their future legal residency status.

About half of survey respondents and their household members who underwent SARS-CoV-2 testing (71 respondents and 81 respondents' household members) reported doing so because they were symptomatic (Fig. 1). Participants who worked outside the home, lived in larger households, or resided with someone who tested positive for SARS-CoV-2 were most likely to test positive (unadjusted odds ratios of 2.5, 1.2 , and 12.9, respectively - see Table 2). Investigation participants indicated that the consequences of a positive SARSCoV-2 test can be enormous, describing people who lost their jobs, were evicted from their homes, infected loved ones, and died.

Survey respondents were overwhelmingly willing to participate in contact tracing, with $96 \%$ feeling comfortable sharing information about their close contacts with the health department. However, qualitative evaluation participants estimated this percentage to be closer to $50 \%$. Factors affecting willingness to participate in contact tracing included hesitancy on how contact information would be used and anxiety over identifying loved ones who are undocumented.

\section{Difficulties in the Workplace}

"One of the things I see a lot is the gardeners... they're working, they're sweating, they're breathing hard, and then you've got five or six guys climbing into a truck together, and you've got air circulating and there's no room for it to go so if any one of those people gets sick, they're probably giving it to everyone else there...Folks that are cleaning homes, you've got four women packing into a car... and they have to work, right? They need to feed their families." -key informant

Among employed survey respondents (58\%), most (59\%) worked in the construction or restaurant industries (Table 1). 
Table 2 Factors associated with positive SARS-CoV-2 test among survey respondents $(n=161)$ June 2020

\begin{tabular}{|c|c|c|c|c|c|c|}
\hline & \multicolumn{3}{|c|}{ Univariable logistic regression } & \multicolumn{3}{|c|}{ Multivariable logistic regression } \\
\hline & OR & $95 \% \mathrm{CI}$ & $p$ value & OR & $95 \% \mathrm{CI}$ & $p$ value \\
\hline Total number in household & 1.2 & $1.02-1.4$ & 0.02 & 1.2 & $1.03-1.5$ & 0.04 \\
\hline Employed (respondent) & 2.0 & $0.9-4.5$ & 0.20 & 2.5 & $1.006-6.3$ & 0.05 \\
\hline Household member tested positive & 15.4 & $3.8-62.2$ & 0.0002 & 12.9 & $3.5-46.8$ & 0.002 \\
\hline
\end{tabular}

Respondents who reported any positive SARS-CoV-2 diagnostic test result ( 28 respondents) compared to those who reported only testing negative (38) or never being tested (90). Excluded respondents who were tested and had unknown test results. Adjusted for sex, age, and jurisdiction. Unweighted sample size $n=177$
Among respondents with employed household members $(81 \%)$, most household members $(75 \%)$ also worked in the construction or restaurant industries. Qualitative evaluation participants reported that the majority of employers made no social distancing accommodations, did not provide or require personal protective equipment (PPE), and did not notify employees when coworkers tested positive for SARS-CoV-2. Participants repeatedly wished a local government entity would mandate COVID-19 safety standards for employers. Most reported being too afraid to say anything for fear of retribution; despite the dangers, they needed to continue working to make ends meet.

More than a quarter $(27 \%)$ of survey respondents reported inability to social distance at work. Focus group participants noted that social distancing was difficult in the shared vehicles people used to travel to work and at lunchtime. Workers in jobs requiring physical labor, particularly outdoors, reported difficulty wearing masks.

\section{Difficulties at Home}

"It's the proximity in which they live, it's not the amount of people, it's the proximity in which they live.
The typical Hispanic family lives in two or no more than three bedrooms and they're large enough to occupy completely those spaces." -key informant

The mean household size among survey respondents was 5.6 (Table 1), compared with 2.6 in Virginia overall [13]. Investigation participants reported that social distancing in such crowded conditions was difficult or impossible; a quarter of survey respondents ( $25 \%$ ) reported they would be unable to social distance at home if needed, and qualitative evaluation participants estimated the percentage was much higher. Qualitative evaluation participants reported multiple accounts of someone catching COVID-19 at work and then all household members falling ill over subsequent weeks. Increased household size was associated with increased likelihood of testing positive for COVID-19, and those with a household member who tested positive for SARS-CoV-2 were more likely to test positive themselves (Table 2).

In addition, participants reported that the pandemic had a marked effect on mental health. Nearly a quarter $(23 \%)$ of survey respondents reported increased anxiety and stress (Fig. 2). Almost half (47\%) of respondents reported job loss or reduction in work hours, with difficulties paying rent, buying food, or affording other necessities among $25 \%$ of all
Fig. 1 Survey respondents' reasons for undergoing SARSCoV-2 testing $(n=161)$ June 2020

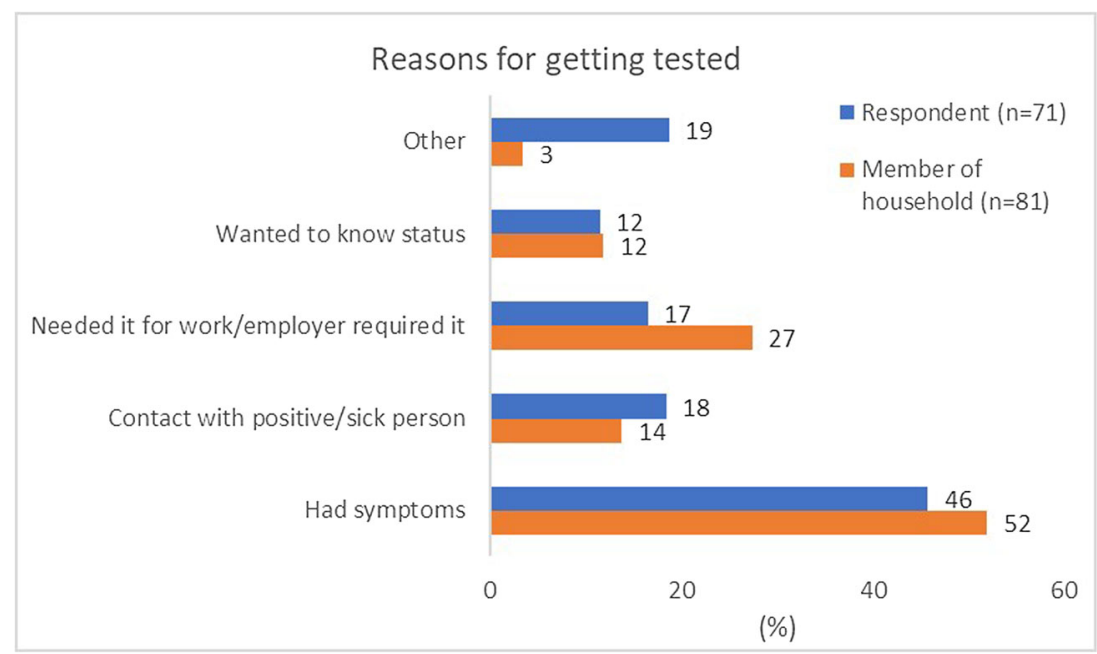

Survey weights applied; sample weighted on age, sex, and jurisdiction. Unweighted sample size $n=177$ 
Fig. 2 Impact of COVID-19 on survey respondents $(n=161)$ June 2020
How have you been impacted by COVID-19?

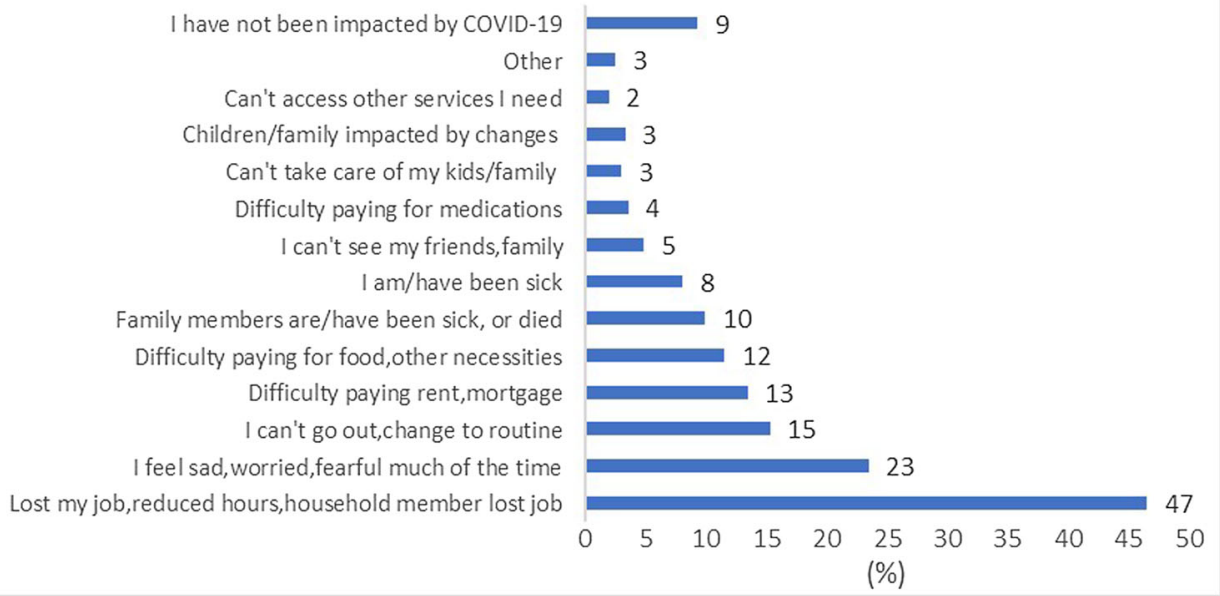

Survey weights applied; sample weighted on age, sex, and jurisdiction. Unweighted sample size $\mathrm{n}=177$. Results sum to greater than $100 \%$ due to multiple responses by respondents respondents. A further concern described by qualitative evaluation participants was that community members who are undocumented are not eligible for many aid programs. Generalized worry was expressed about the aggressive effort needed to keep families, particularly children, safe and the high toll the disease has taken on loved ones.

Finally, qualitative evaluation participants reported that social distancing precautions have drastically curtailed several cornerstones of Hispanic and Latino culture, including physical touching, religious services, and large social gatherings. They indicated that increased economic stressors coupled with the loss of traditional social support systems magnified the impact of COVID-19 on their communities.

\section{Discussion}

This assessment identified multiple constraints which impeded COVID-19 mitigation efforts in PWHD's Hispanic or Latino communities. Many common themes were identified across all three data collection modalities, underscoring the importance of these findings. Limited understanding of and adherence to key COVID-19 prevention practices, lack of reliable COVID-19 information sources (particularly locallevel information), inability to work remotely, crowded living conditions, and difficulty accessing SARS-CoV-2 testing and receiving results all hindered investigation participants' efforts to keep themselves and their families safe. Furthermore, loss of traditional support networks and food insecurity magnified the pandemic's effect on their lives. However, the investigation also identified many solutions to these issues, and thanks to the rapid nature of the assessment, the PWHD and its partners have already begun to act upon them.
First and foremost, this investigation highlighted the importance of culturally competent outreach. While PWHD's local government offices had extensive COVID-19 resources available, including multiple informative websites and a call center, such resources were underutilized by Hispanic or Latino residents. The investigation identified that to reach these populations, information must be in Spanish and channeled through trusted entities, such as church leaders or local nonprofits. Pre-existing health programs that already worked closely with Hispanic or Latino communities have been employed by other jurisdictions to quickly provide trusted information on COVID-19 [14, 15]. Community health workers have also been critically important to reaching vulnerable populations during the pandemic $[14,16]$. Furthermore, fostering strong relationships with local Hispanic or Latino-serving organizations may pay dividends for reducing overall health disparities [17-19].

Second, this investigation uncovered the benefit of creating COVID-19 communication materials in a wide range of modalities. Prince William County, Manassas, and Manassas Park had an extensive web presence with many pages of thorough English-language guidelines, but more than half of survey participants spoke little or no English and had less than a high school education. Hispanic or Latino populations have been shown to have lower COVID-19 knowledge than other ethnic groups [20, 21]. Investigation participants suggested that making COVID19 information available in video or picture format would be more accessible, particularly if such information was displayed on television or social media. Using pictures and videos to clarify concepts has been helpful in other populations with low health literacy $[22,23]$. In addition, many guidelines exist for using social media for health promotion [24-26]. Emergency notification text messaging 
services have been used by some local governments to disseminate COVID-19 information [15]. The investigation also identified specific questions about COVID-19 prevention, such as how often to wash masks, when to wear gloves, and how to stay safe in crowded places, that the PWHD can directly answer in future health communication initiatives.

Poor access to SARS-CoV-2 testing was noted by many investigation participants. In addition to providing local testing site information in Spanish, other jurisdictions have reached underserved communities by sending testing teams to neighborhoods at risk, particularly outside of normal business hours $[27,28]$. People who are undocumented may also worry that accessing governmental SARS-CoV-2 testing may adversely affect their legal status, so it is important to explicitly emphasize patient confidentiality and any identification requirements for testing [29].

This investigation identified work outside of the home as a significant risk factor for SARS-CoV-2 infection for everyone in a household; therefore, assuring COVID-19 safety protections for workers is critically important to reducing disease spread. One solution could be to establish a community of practice among local employers to share methods for protecting their workers; there are many best practice resources available $[30,31]$. Strongly enforced universal masking policies have also been shown to significantly reduce SARS-CoV-2 spread, and increased availability of masks is also important [32].

Finally, the COVID-19 pandemic has had effects on other non-infectious disease issues. Food insecurity has intensified and mental health has worsened among investigation participants. To maximize the impact of public health interventions, it is important to consider such collateral needs when providing COVID-19 services. For example, food pantry sites have been used to disseminate information on COVID-19 testing [14]. School buses, unused while schools are closed, have also been employed to deliver food to needy families [33]. Expanded use of telehealth mental health services, particularly in Spanish, may also help mitigate the psychiatric effects of the pandemic on the community [34]. Efforts to increase social connectedness and reduce financial strain may also be helpful [35].

These findings are subject to a few limitations. The investigation was implemented in a short time with a limited number of Hispanic or Latino community members and advocates. Respondents from Manassas were overrepresented in the survey sample due to the increased willingness of this city's residents to participate. While investigation participants identified many of the same issues and themes, it is possible that these findings are not representative of the entire Hispanic or Latino community in PWHD. In addition, it is possible that survey participants who were not tested for SARS-CoV-2 could have still contracted COVID-19.
This investigation's methods can serve as a model for other jurisdictions wishing to determine if they are meeting the needs of special populations. Data collection took place over two weeks and data cleaning and analysis in one week, meaning that datadriven, actionable information was available in less than a month. Considering that saturation in the focus groups and key informant interviews was reached after approximately half the data was collected, this timeline could be even further reduced. This method allowed the PWHD and its partners to enact locally specific public health improvements for Hispanic or Latino residents at a pace that was responsive to the fast pace of the pandemic, and could be similarly used by other jurisdictions for a rapid pulse check of groups at higher risk of COVID-19.

\section{Conclusions}

This investigation used a rapid, multi-pronged method of assessing the needs and limitations encountered by Hispanic or Latino residents of PWHD during the COVID-19 pandemic. This allowed locally specific, actionable results to be identified quickly and acted upon quickly. This method can serve as a model for other jurisdictions to evaluate the needs of and services provided to diverse populations.

Furthermore, the investigation identified many findings that may be generalizable to other public health departments caring for similar Hispanic or Latino populations, such as the need for locally specific Spanish-language COVID-19 resources, more flexible SARS-CoV-2 testing strategies, improvement in enforcement of protections for essential workers, and attention to food insecurity and mental health during the pandemic. This investigation also underscored the paramount importance of culturally competent outreach, including partnering with agents trusted by Hispanic and Latino communities.

Code Availability Code is available on request.

Funding This work was undertaken by the authors as part of their normal duties at the Centers for Disease Control and Prevention (CDC) and the Virginia Department of Health. No additional funding was provided.

Data Availability Data are available on request.

\section{Declarations}

Ethics Approval and Consent to Participate This work was approved by the ethics committee at CDC. All participants were adults and provided verbal informed consent before participation.

Consent for Publication All authors have provided consent for publication.

Conflict of Interest The authors declare no competing interests. 


\section{References}

1. United States Census Bureau. Quick facts: Prince William County, Virginia: United States Department of Commerce; 2019. https:// w w w . census.gov/qui ckfacts/fact/table/ princewilliamcountyvirginia,VA/PST045219.

2. Virginia Department of Health. COVID-19 in Virginia: demographics: Virginia Department of Health; 2020. https://www.vdh. virginia.gov/coronavirus/coronavirus/covid-19-in-virginiademographics/.

3. Kaiser Family Foundation. COVID-19 cases by race/ethnicity: Kaiser Family Foundation; 2020. https://www.kff.org/other/stateindicator/covid-19-cases-by-race-ethnicity/?currentTimeframe= 0 \&sortModel $=\% 7 \mathrm{~B} \% 22$ colId $\% 22: \% 22$ Location $\% 22, \% 22$ sort $\%$ 22:\%22asc\%22\%7D.

4. Macias Gil R, Marcelin JR, Zuniga-Blanco B, Marquez C, Mathew T, Piggott DA. COVID-19 pandemic: disparate health impact on the Hispanic/Latinx population in the United States. J Infect Dis. 2020;222:1592-5.

5. United States Census Bureau. Quick facts: United States: United States Department of Commerce; 2019. https://www.census.gov/ quickfacts/fact/table/US/PST045219.

6. Centers for Disease Control and Prevention. Health equity considerations and racial and ethnic minority groups: Centers for Disease Control and Prevention; 2020. https://www.cdc.gov/coronavirus/ 2019-ncov/community/health-equity/race-ethnicity.html.

7. Price-Haywood EG, Burton J, Fort D, Seoane L. Hospitalization and mortality among black patients and white patients with Covid19. N Engl J Med. 2020;382(26):2534-43.

8. Laurencin CT, McClinton A. The COVID-19 pandemic: a call to action to identify and address racial and ethnic disparities. J Racial Ethn Health Disparities. 2020;7(3):398-402.

9. Weng CH, Saal A, Butt WWW, Chan PA. Characteristics and clinical outcomes of COVID-19 in Hispanic/Latino patients in a community setting: a retrospective cohort study. J Med Virol. 2020. https://pubmed.ncbi.nlm.nih.gov/32558963/.

10. Rentsch CT, Kidwai-Khan F, Tate JP, et al. Covid-19 by race and ethnicity: a national cohort study of 6 million United States veterans: medRxiv : the preprint server for health sciences; 2020. https://www.ncbi.nlm.nih.gov/pmc/articles/PMC7273292/.

11. Bui DP, McCaffrey K, Friedrichs M, LaCross N, Lewis NM, Sage K, Barbeau B, Vilven D, Rose C, Braby S, Willardson S, Carter A, Smoot C, Winquist A, Dunn A Racial and ethnic disparities among COVID-19 cases in workplace outbreaks by industry sector - Utah, March 6-June 5, 2020. MMWR Morb Mortal Wkly Rep 2020;69(33):1133-1138. https://www.ncbi.nlm.nih.gov/pmc/ articles/PMC7439983/.

12. Centers for Disease Control and Prevention. Symptoms of coronavirus: Centers for Disease Control and Prevention; 2020. https:// www.cdc.gov/coronavirus/2019-ncov/symptoms-testing/ symptoms.html.

13. United States Census Bureau. Quick facts: Virginia: United States Department of Commerce; 2019. https://www.census.gov/ quickfacts/VA.

14. Calo WA, Murray A, Francis E, Bermudez M, Kraschnewski J. Reaching the Hispanic community about COVID-19 through existing chronic disease prevention programs. Prev Chronic Dis. 2020;17:E49.

15. Velasquez D, Uppal N, Perez N. Equitable access to health information for non-English speakers amidst the novel coronavirus pandemic. Health Affairs Blog. 2020. https://www.healthaffairs.org/ do/10.1377/hblog20200331.77927/full/.
16. Smith DO, Wennerstrom A. To strengthen the public health response to COVID-19, we need community health workers. Health Affairs Blog. 2020. https://www.healthaffairs.org/do/10.1377/ hblog20200504.336184/full/.

17. Hull PC, Canedo J, Aquilera J, Garcia E, Lira I, Reyes F. Assessing community readiness for change in the Nashville Hispanic community through participatory research. Progress in community health partnerships : research, education, and action. 2008;2(3):185-94.

18. Fernandez M, Shinew KJ. One Agency's contribution to creating a culture of health in a Latinx community. Health equity. 2019;3(1): $9-12$.

19. Wirshup MB, Poutasse S, Deverlis A. Developing a community response: collaborating locally on immigrant care. Pediatr Clin N Am. 2019;66(3):575-87.

20. Jones J, Sullivan PS, Sanchez TH, Guest JL, Hall EW, Luisi N, Zlotorzynska M, Wilde G, Bradley H, Siegler AJ Similarities and differences in COVID-19 awareness, concern, and symptoms by race and ethnicity in the United States: cross-sectional survey. J Med Internet Res 2020;22(7):e20001. https://www.ncbi.nlm.nih. gov/pmc/articles/PMC7357692/.

21. Alobuia WM, Dalva-Baird NP, Forrester JD, Bendavid E, Bhattacharya J, Kebebew E. Racial disparities in knowledge, attitudes and practices related to COVID-19 in the USA. J Public Health (Oxford, England). 2020;42(3):470-8.

22. Kountz DS. Strategies for improving low health literacy. Postgrad Med. 2009;121(5):171-7.

23. Yeung DL, Alvarez KS, Quinones ME, Clark CA, Oliver GH, Alvarez CA, et al. Low-health literacy flashcards \& mobile video reinforcement to improve medication adherence in patients on oral diabetes, heart failure, and hypertension medications. J Am Pharmacists Assoc. 2017;57(1):30-7.

24. Korda $\mathrm{H}$, Itani $Z$. Harnessing social media for health promotion and behavior change. Health Promot Pract. 2013;14(1):15-23.

25. Grajales FJ 3rd, Sheps S, Ho K, Novak-Lauscher H, Eysenbach G. Social media: a review and tutorial of applications in medicine and health care. J Med Internet Res. 2014;16(2):e13.

26. Moorhead SA, Hazlett DE, Harrison L, Carroll JK, Irwin A, Hoving C. A new dimension of health care: systematic review of the uses, benefits, and limitations of social media for health communication. J Med Internet Res. 2013;15(4):e85.

27. Currie J, Adamson J, Bowden B, Woolls J, Jones R, Healy B, et al. Impact of a novel community testing pathway for people with suspected COVID-19 in Wales: a cost-minimisation analysis. BMJ Open. 2020;10(8):e038017.

28. Los Angeles County Department of Public Health. Mobile COVID19 pop-up testing locations: City of Los Angeles; 2020. https:// corona-virus.la/mobile-pop-covid-19-testing-locations.

29. Behbahani S, Smith CA, Carvalho M, Warren CJ, Gregory M, Silva NA. Vulnerable immigrant populations in the New York Metropolitan Area and COVID-19: lessons learned in the epicenter of the crisis. Acad Med. 2020;95:1827-30.

30. National Partnership for Women and Families, National Employment Law Project. Employer best practices: policies to support workers during the coronavirus pandemic. National Partnership for Women and Families. 2020. https://www.nelp. org/publication/employer-best-practices-policies-support-workerscoronavirus-pandemic/.

31. Centers for Disease Control and Prevention. Interim guidance for businesses and employers responding to coronavirus disease 2019 (COVID-19), May 2020: Centers for Disease Control and Prevention. p. 2020. https://www.cdc.gov/coronavirus/2019-ncov/ community/guidance-business-response.html. 
32. Brooks JT, Butler JC, Redfield RR. Universal masking to prevent SARS-CoV-2 transmission - the time is now. JAMA. 2020;324(7): 635-7.

33. Kinsey EW, Kinsey D, Rundle AG. COVID-19 and food insecurity: an uneven patchwork of responses. J Urban Health. 2020;97(3): 332-5.

34. Hailey D, Roine R, Ohinmaa A. The effectiveness of telemental health applications: a review. Can J Psychiatr. 2008;53(11):769-78.
35. Czeisler M, Lane RI, Petrosky E, Wiley JF, Christensen A, Njai R, et al. Mental health, substance use, and suicidal ideation during the COVID-19 pandemic - United States, June 24-30, 2020. MMWR Morb Mortal Wkly Rep. 2020;69(32):1049-57.

Publisher's Note Springer Nature remains neutral with regard to jurisdictional claims in published maps and institutional affiliations. 